\title{
High or standard initial dose of budesonide to control mild-to-moderate asthma?
}

\author{
P. Chanez*, R. Karlstrom ${ }^{\#}$, P. Godard*
}

High or standard initial dose of budesonide to control mild-to-moderate asthma? P. Chanez, R. Karlstrom, P. Godard. (C) ERS Journals Ltd 2001.

ABSTRACT: Guidelines on the use of inhaled steroids in asthma advocate that the daily dose should be chosen according to the severity of the disease. However, the question of the optimal starting dose remains to be properly addressed, as does the issue of the adjustment in dose required for a given patient.

Whether a high initial dose of budesonide $(800 \mu \mathrm{g} b . i . d)$ was more efficacious than a standard dose $(200 \mu \mathrm{g}$ b.i.d) in controlling mild-to-moderate asthma was investigated, and whether the dose could be decreased, based on peak expiratory flow (PEF), symptom-score, $\beta_{2}$-agonist use in a double-blind, randomized, parallel-group 18-week study.

One-hundred and sixty-nine patients (mean age 38 yrs, mean forced expiratory volume in one second $74 \%$ predicted) were enrolled. No difference was detected between the two groups in improvement in morning PEF $\left(+61 \mathrm{~L} \cdot \mathrm{min}^{-1}\right.$ in the high-dose group, $+60 \mathrm{~L} \cdot \mathrm{min}^{-1}$ in the standard-dose group by 16 weeks). Morning and evening PEF values stabilized before the end of the first 4 weeks.

No difference between groups was observed in symptom score, $\beta_{2}$-agonist use, number of exacerbation per interval and the best forced expiratory volume in one second achieved. The proportion of subjects being able to decrease the doses of budesonide was similar in both treatment strategies. It is concluded that both high and standard initial doses are equally effective in controlling symptoms and improving lung function in mildto-moderate asthma.

Eur Respir J 2001; 17: 856-862.
*Clinique des Maladies Respiratoires Hôpital Arnaud de Villeneuve, CHU de Montpellier, France and ${ }^{\#}$ AstraZeneca R\&D, Lund, Sweden.

Correspondence: P. Chanez Hôpital Arnaud de Villeneuve CHU de Montpellier 34295Montpellier-Cedex 5

France

Fax: 33467521848

Keywords: Airway pharmacology budesonide

mild-to-moderate asthma treatment strategy

Received: January 152000 Accepted after revision January 15 2001
It is well established that inhaled corticosteroids (ICSs) effectively control symptoms and improve lung function in asthmatic patients [1,2]. Over recent years, guidelines have varied in their recommendations for starting doses of ICSs. When the present study was performed, most of the current guidelines advocated a stepwise approach, starting with low doses [3, 4]. However, the benefit of starting with a high dose of ICSs was illustrated in a long-term study investigating the effect of budesonide pressurized metered-dose inhaler (pMDI) $1,200 \mu \mathrm{g}$ daily in newly diagnosed mild asthma; a clear improvement in daily peak expiratory flow (PEF) was seen within a few days in the group treated with budesonide. On the other hand, in another study in patients with mild asthma, a low dose of budesonide, $400 \mu \mathrm{g}$ daily, was also seen to increase morning PEF and decrease nocturnal symptoms and $\beta_{2}$-agonist use $[5,6]$. A few well-controlled studies in severe asthma have succeeded in demonstrating a dose-response to inhaled steroids [7-9], but this has been difficult to show in mild-to-moderate asthma.

Thus, the question of the optimal starting dose still remains to be properly addressed, as does the issue of the adjustment in dose required for a given patient. Therefore, the present double-blind, randomized study was undertaken to assess if: 1) a high initial dose of ICSs (budesonide $800 \mu \mathrm{g}$ b.i.d.) was more efficacious than a standard dose (budesonide $200 \mu \mathrm{g}$ b.i.d.) in controlling symptoms and improving lung function; and 2) the daily dose could be decreased rapidly in the high-dose group, to a minimum maintenance dose, based on assessment of symptoms, PEF and use of $\beta_{2^{-}}$ agonists, in mild-to-moderate asthmatic patients.

\section{Patients}

Adult patients, aged 18-70 yrs, with uncontrolled asthma, not currently on inhaled steroid treatment or on inhaled steroids up to $500 \mu \mathrm{g} \cdot \mathrm{day}^{-1}$ (beclomethasone dipropionate by metered dose inhaler) or on a constant dose of long-acting theophylline during the past 2 weeks, were eligible for the treatment phase.

Asthma was considered to be uncontrolled if the patients had experienced daily nocturnal symptoms, wheezing and $\beta_{2}$-agonists requirement (at least 2 puffs $\cdot$ day $^{-1}$ ) during the last 7 days. Measured PEF, should have demonstrated a mean decrease of $>20 \%$ in morning PEF or a mean diurnal variation in PEF of $>20 \%$ (difference between the highest and the lowest $\mathrm{PEF}$, divided by the highest PEF) during the last 7 days of run-in.

Patients had to show a forced expiratory volume in one second (FEV1) response to $\beta_{2}$-agonist $>12 \%$ of the 
predicted value. Patients with a prebronchodilator FEV1 value of $<55 \%$ pred were ineligible for safety reasons.

The patients who had used nasal steroids during the past month or oral and parenteral steroids were excluded. The patients treated with leucotrienes antagonists, during the past, or who had had an exacerbation or airway infection during the past month were also excluded. During the study, steroids other than inhaled budesonide were not allowed, nor were nebulized or parenteral $\beta_{2}$-agonists.

\section{Study design}

This was a double-blind and double-dummy, randomized, parallel-group study, conducted at 18 centres in France. It comprised a 2-week run-in period, and four active treatment periods, each of 4 weeks duration. There were six clinic visits: at the start of the run-in period, at the start of active treatment and after 4,8 , 12 and 16 weeks of treatment.

During run-in, patients continued with their current asthma therapy (short-acting inhaled $\beta_{2}$-agonists were allowed on an as needed basis, long-acting theophylline) and compliance and capacity to participate in the study were assessed. Patients were then randomized by centre, in a block size of four, according to a computer generated randomization list, into two treatment groups receiving budesonide (Pulmicort $\mathbb{R}$ ) via Turbuhaler® (AstraZeneca, Sweden) one starting on $800 \mu \mathrm{g}$, and the other on $200 \mu \mathrm{g}$, twice daily (fig. 1). At the end of each active treatment period, the investigator assessed whether the patient's asthma was controlled; if so, the daily dose was halved, if not the patients continued on the same dose as previously. All patients went through this assessment procedure, but only patients in the high-dose group actually had their dose changed (fig. 1).

Turbuhaler $\mathbb{R}$ inhalers delivering different amounts of drug per inhalation $(100,200400$ and $800 \mu \mathrm{g}$ Turbuhalers $\mathbb{R}$ used 1 puff b.i.d.), were used in order to

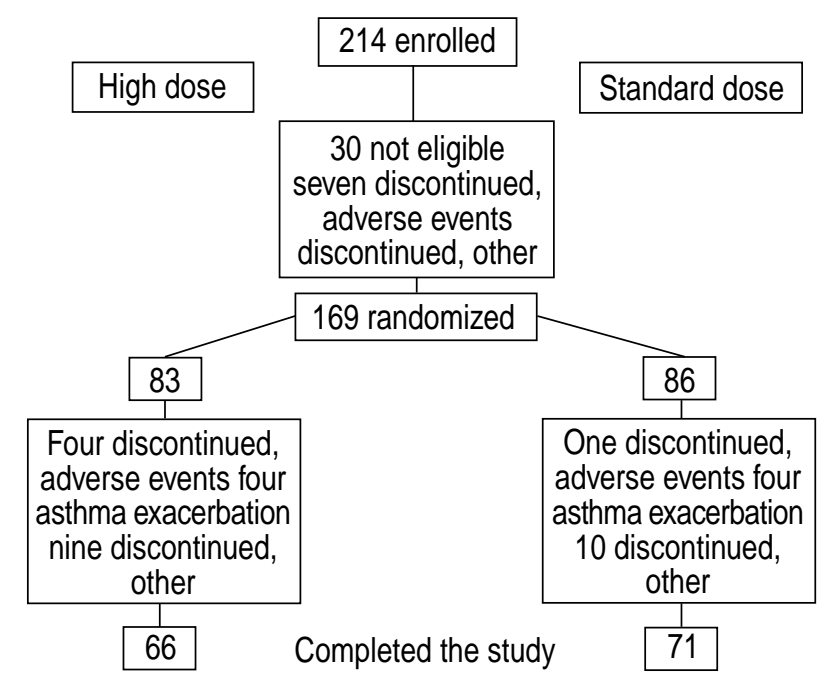

Fig. 1. - Progress of patients through the study. keep the number of inhalations constant throughout the study. There were four dose levels of drug: level 1 for the initial dose, level 2 for the first decreased dose, level 3 for the second decreased dose, level 4 for the third and last decreased dose. Level 1-4 inhalers for the standard-dose group contained the same dose throughout. The inhalers were individually packed in plastic bags and the level number appeared only on the bags. The investigator selected the level and took the inhaler out of the plastic bag before handing it over to the patient.

The study was approved by the medical ethics committee of the Montpellier Hospital and written informed consent was obtained from all patients at the beginning of the study.

\section{Investigations and outcomes}

Clinical outcomes: symptom diaries, visits and adverse events

Every day during the run-in period and during the four active treatment periods, the patients performed morning (prebronchodilator) and evening PEF measurements with a mini-Wright Peak Flow Meter, (Clement Clark International, London, UK) and recorded the best of three exhalations in a diary. They also recorded their use of $\beta_{2}$-agonists day and night, their symptoms of asthma (cough, wheeze, dyspnoea, tightness of the chest) according to a fourgrade scale $(0-3)$.

At each clinic visit a control score was calculated based on the morning PEF; amount of $\beta_{2}$ consumption and number of symptoms (nocturnal symptoms, cough, wheeze) (0-3) taking place during the last 7 days of the period.

Patients who experienced an asthma exacerbation (symptoms increase lasting at least 2 consecutive days and/or unscheduled requirement of care for asthma) requiring a short course of oral steroid treatment were withdrawn from the study.

Asthma was considered to be controlled if PEF increased by $5 \%$ over the run-in period, FEV1 increased over the initial value measured at the end of the run-in period, the amount of puffs of $\beta_{2}$-agonists decreased compared to the run-in period amount and that the symptoms score decreased compared with the run-in period. If asthma was controlled i.e. all criteria being fulfilled, a dose reduction was possible. This control score is comparable to a recently published asthma control questionnaire [7].

Hoarseness irritation in the throat and candidiasis (according to a $0-3$ scale) were investigated at each visit. Blood sampling for eosinophil counts was obtained.

\section{Spirometry}

FEV1, forced vital capacity and reversibility to $1.0 \mathrm{mg}$ terbutaline sulphate administered as Bricanyl $(\mathrm{R})$ Turbuhaler $\mathbb{R}$, were also performed at each clinic visit. 


\section{Statistical analysis}

The primary efficacy variables were the diary data. For diary data, spirometry, eosinophil count and local side-effects, the change from baseline (the last 7 days of the run-in period) to the last 7 days of each treatment period was calculated, and the groups were compared by t-tests. The comparison between the groups with respect to the mean daily dose at the end of the study was analysed by Wilcoxon rank sum test. All tests were two-tailed and $\mathrm{p}$-values $\leqslant 0.05$ were considered statistically significant.

Based on previous experience, the standard deviation for a change in PEF between two periods was estimated to be $15 \%$ pred. Having 80 evaluable patients in each group would give an $80 \%$ chance of finding a significant difference if the true difference in PEF was $6.5 \%$ of the pred, using a t-test on a $5 \%$ level. A $5 \%$ increase in morning PEF was considered clinically relevant.

The analysis of all patients who received active treatment $(n=169)$ produced results similar to that of all patients who completed the study according to protocol $(n=120)$. The results presented below are those of the intention-to-treat analysis.

\section{Results}

Two-hundred and fourteen patients were included in the run-in period and (169) received active treatment. At study start, the two treatment groups were very similar with respect to all variables (table 1). The outcome of the dose adjustment procedure is shown in figure 2 . The proportion of patients qualifying for dose

Table 1.-Patient characteristics

High-dose Standard-dose

Subjects $n$

Age yrs

Sex ratio (male/female)

Duration of asthma yrs

Previous use of ICS \%

Use of theophylline \%

Allergy \%*

Smoking past or current $\%$

Nocturnal symptoms ${ }^{\#} 0-3$

Daily symptoms ${ }^{\#} 0-3$

$\beta_{2}$ at night ${ }^{\#}$ puffs

$\beta_{2}$ daily" puffs

FEV $1 \%$ pred

Reversibility $\%$
Number of eosinophils $10^{9} \cdot \mathrm{L}^{-1}$

\begin{tabular}{cc}
83 & 86 \\
$38.0(18-68)$ & $38.0(18-65)$ \\
$44 / 40$ & $41 / 45$ \\
$16.0(0-49)$ & $17.0(0-52)$ \\
49 & 51 \\
34 & 27 \\
84 & 82 \\
33 & 37 \\
$0.80 \pm 0.66$ & $0.80 \pm 0.73$ \\
$0.89 \pm 0.63$ & $0.89 \pm 0.68$ \\
$1.2 \pm 1.3$ & $1.1 \pm 1.5$ \\
$2.4 \pm 1.8$ & $2.5 \pm 2.2$ \\
$74.4 \pm 16.0$ & $74.1 \pm 13.6$ \\
$13.7 \pm 9.1$ & $17.0 \pm 9.8$ \\
$0.32 \pm 0.21$ & $0.43 \pm 0.33$ \\
\hline
\end{tabular}

Data presented as means (ranges) or mean \pm SD unless otherwise stated. High-dose: $800 \mu \mathrm{g}$ b.i.d.; standard-dose: $200 \mu \mathrm{g}$ b.i.d.; ICS: inhaled corticosteroids; *: determined using prick test; ${ }^{\#}$ : three patients $<12 \%$ (protocol deviation).

reduction was similar in the two groups at each assessment stage. By the end of the study, the mean daily dose in the high-dose group had been tapered to $600 \mu \mathrm{g}$.

Morning PEF increased in both groups during the first 4 weeks of active treatment: by $48 \mathrm{~L} \cdot \mathrm{min}^{-1}$ in the high-dose group and by $46 \mathrm{~L} \cdot \mathrm{min}^{-1}$ in the standarddose group. After 16 weeks of treatment, morning PEF had increased from baseline by $61 \mathrm{~L} \cdot \mathrm{min}^{-1}$ and 60 $\mathrm{L} \cdot \mathrm{min}^{-1}$ in the high- and standard-dose groups, respectively (fig. 3). The difference between the groups was not statistically significant at any time

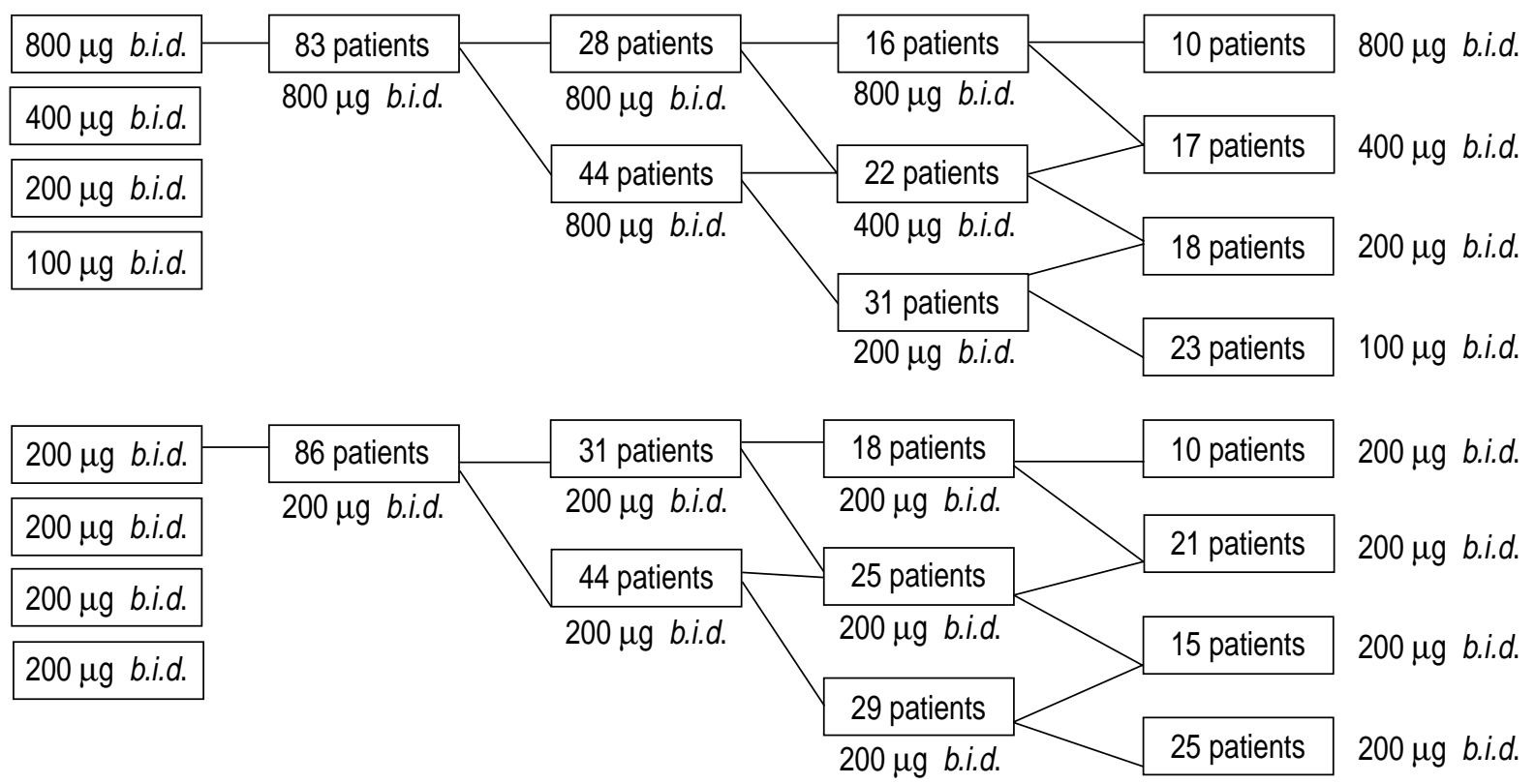

Weeks

Fig. 2.-Study design and outcome of the dose adjustment procedures. 


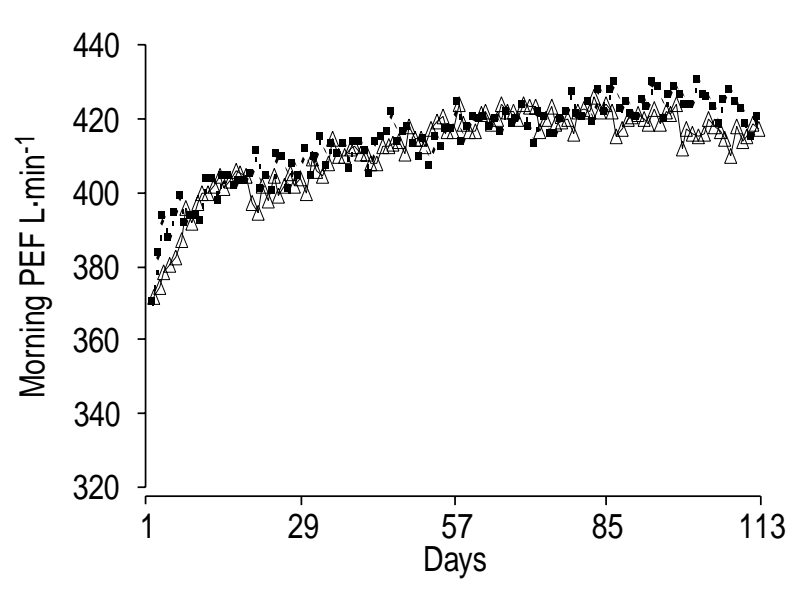

Fig. 3.-Changes in morning peak expiratory flow (PEF) during the study. $\triangle(-)$ : High-dose budesonide, $800 \mu \mathrm{g}$ b.i.d. $\square(\cdots)$ : standard-dose budesonide, $200 \mu \mathrm{g}$ b.i.d.

point (table 2). Evening PEF increased by $24 \mathrm{~L} \cdot \mathrm{min}^{-1}$ in the high-dose group and by $11 \mathrm{~L} \cdot \mathrm{min}^{-1}$ in the standard-dose group during the first 4 weeks of treatment. The difference between the groups was not statistically significant and the improvements were maintained throughout the following 12 weeks of the study. Asthma symptom score day and night and use of $\beta_{2}$-agonist day and night also improved: the largest increase occurred after the first treatment period in both groups, and was of the same magnitude (table 2). The number of asthma exacerbation was limited and similar in the two groups.

FEV1 increased during the first treatment period by $7.2 \%$ pred value in the high-dose group and by $7.7 \%$ in the standard-dose group. No further increase in FEV1 was recorded during the rest of the study (fig. 4).

In the high-dose group, the maximum improvement occurred in the first treatment period and was subsequently maintained. The maximum response was reached during the second treatment period in the standard-dose group, reaching the same level as the

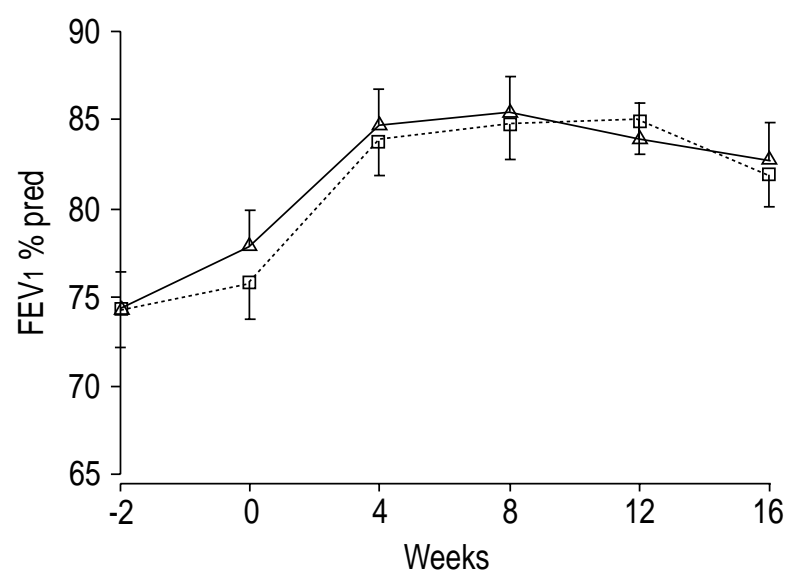

Fig. 4. - Forced expiratory volume in one second (FEV1: percentage of predicted normal) during the study. $\triangle(-)$ : High-dose budesonide, $800 \mu \mathrm{g}$ b.i.d.; $\square(\cdots)$ : standard-dose budesonide, $200 \mu \mathrm{g}$ b.i.d.

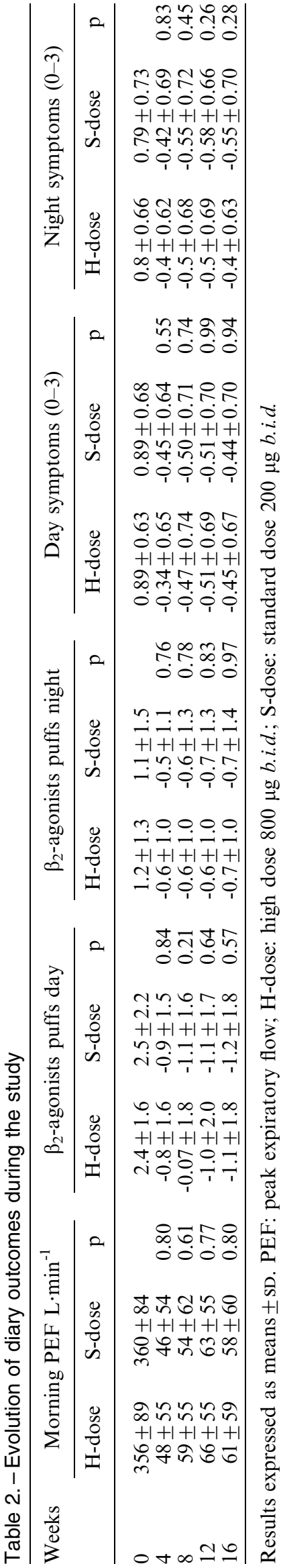


Table 3. - Evolution of eosinophil count and reversibility during the study

\begin{tabular}{lccccc}
\hline Weeks & Eosinophils in blood $10^{9} \cdot \mathrm{L}^{-1}$ & & \multicolumn{2}{c}{ Reversibility $\%$} \\
\cline { 2 - 3 } \cline { 5 - 6 } & H-dose & S-dose & & H-dose & S-dose \\
\hline 0 & $0.32 \pm 0.22$ & $0.47 \pm 0.43$ & & $13.7 \pm 9.1$ & $17.0 \pm 9.8$ \\
4 & $0.13 \pm 0.23$ & $-0.07 \pm 0.38$ & & $-2.4 \pm 9.5$ & $-3.0 \pm 11.6$ \\
8 & $-0.07 \pm 0.23$ & $-0.04 \pm 0.44$ & & $-2.2 \pm 9.7$ & $-4.5 \pm 11.1$ \\
12 & $-0.07 \pm 0.26$ & $-0.09 \pm 0.42$ & & $-2.4 \pm 10.0$ & $-5.8 \pm 10.4$ \\
16 & $-0.05 \pm 0.25$ & $-0.11 \pm 0.24$ & & $-3.7 \pm 10.2$ & $-5.7 \pm 9.5$ \\
\hline
\end{tabular}

Results expressed as means + SD. S-dose $=$ standard dose $200 \mu \mathrm{g}$ b.i.d.; H-dose $=$ high dose $800 \mu \mathrm{g}$ b.i.d. .

high-dose group and then remaining unchanged. There was thus a one-period delay between the groups. However, the difference in improvement after the first period was not statistically significant (table 3 ).

The reversibility to $\beta_{2}$-agonist decreased in both groups; as the population was not severely obstructed the change in reversibility was not unexpected. The eosinophil counts decreased in both groups; the highdose group reached a minimum after 4 weeks of treatment and the standard-dose group after 12 weeks, but the difference was not statistically significant (table 3). With regard to local side-effects, no difference was seen between groups regarding candidiasis. Scores for hoarseness and throat irritation were statistically significantly higher for patients in the high-dose group after 8 weeks of treatment, but not at any other time during the study $(p=0.02$ and $p=0.04$, respectively).

A subgroup analysis has been conducted and did not find any statistical significance between previous users and nonusers of ICS (up to $500 \mu \mathrm{g}$ of beclomethasone dipropionate at the entry in the run-in period). Previous intake of inhaled steroids was not found to be associated with any outcome variables including the morning PEF, FEV1 (\% pred) or exacerbation rate.

The effect of smoking on lung function was addressed in a subgroup analysis. At study start, lung function and reversibility to $\beta_{2}$-agonists for smokers were not different from that for the whole population. Mean FEV1 was $74 \%$ pred in both populations and reversibility was $15.6 \%$ in smokers and $15.3 \%$ for the whole population. No significant differences were found in the responses of smokers, nonsmokers and exsmokers, nor in the responses in these groups to highdose or standard-dose treatment. In the high-dose group, morning PEF increased by $38 \mathrm{~L} \cdot \mathrm{min}^{-1}$ in smokers, by $49 \mathrm{~L} \cdot \mathrm{min}^{-1}$ in nonsmokers, and by $50 \mathrm{~L} \cdot \mathrm{min}^{-1}$ in exsmokers. In the standard-dose group, the corresponding increase was $61 \mathrm{~L} \cdot \mathrm{min}^{-1}$ in current smokers, $47 \mathrm{~L} \cdot \mathrm{min}^{-1}$ in nonsmokers and $24 \mathrm{~L} \cdot \mathrm{min}^{-1}$ in exsmokers.

\section{Discussion}

The two starting doses used in the present study produced similar results in the magnitude of clinical improvement, symptom score, use of $\beta_{2}$-agonist and in functional improvement for PEF and FEV1. The improvement was then maintained, in both groups, throughout the step-down phase. Thus, the two strategies were considered equally efficacious.

It is known that dose-response to inhaled steroids was difficult to demonstrate in patients with mild or mild-to-moderate asthma. Data from a dose-response study in patients with moderate-to-severe asthma show a dose-related significant improvement in morning PEF and FEV1 with $200 \mu \mathrm{g}, 400 \mu \mathrm{g}, 800 \mu \mathrm{g}$, and 1,600 $\mu \mathrm{g}$ budesonide daily given via Turbuhaler $(\mathbb{R}$ compared with placebo, but the differences between the higher dose levels are less pronounced [10]. Dose-response in patients with oral steroid-dependent asthma, however, has been easier to show. A study comparing beclomethasone diproprionate over the range 200-1,600 $\mu \mathrm{g}$ daily [9] and a study comparing $400 \mu \mathrm{g}$ and $1,600 \mu \mathrm{g}$ budesonide daily [8], both showed that a greater reduction in oral corticosteroid use could be achieved with the higher doses.

A dose-response is even more difficult to achieve if the observed population is heterogeneous, with large variation in lung function and symptoms. In the present study, although all patients were uncontrolled, half of the patients in each group were currently on inhaled steroids. However, no differences were associated with the previous use of inhaled corticosteroids. These patients already on inhaled steroids might show a lesser response even though the dose is increased, as was seen in severe steroid-dependent asthmatics [11], where the nonresponders to $400 \mu \mathrm{g}$ did not obtain additional benefit when they were given twice the initial dose.

The doses chosen were considered adequate for the severity level under investigation at the time the study was designed. The current recommendations were $400-1,600 \mu \mathrm{g} \cdot \mathrm{day}^{-1}$ via pMDI. Since the study was initiated, it has been shown that lung deposition with Turbuhaler $(\mathbb{R})$ is twice that with pMDI [12, 13], a finding that is supported by results from clinical studies $[14,15]$.

The outcome variables were chosen to reflect clinical practice, PEF, asthma symptom score and FEV1. Outcome variables that reflect changes in bronchial inflammation have recently been shown to have variable correlation with clinical outcomes and may reflect different aspects of the disease [14]. The reasons for this lack of direct relationship between asthma control and the underlying bronchial inflammation is far from being understood. Control of symptoms may not be equivalent to the best possible improvement. The design of this study, where the daily dose was halved on the basis of morning PEF, symptoms, and use of bronchodilators may have precluded further improvement in lung function and airway responsiveness. The strategy of dose adjustment was not supported by the assessment of airway hyperreactivity as reported in a study where better control of asthma was recorded for patients in whom the therapy was adjusted, the level of airway responsiveness and the clinical outcomes, were compared with patients in whom only the clinical outcomes were considered [16]. The different response in lung function and diary variables compared to that for variables more related to the airway inflammation, could be explained by the 
heterogeneity of the patient population, or by the duration of the disease itself. The mean duration of asthma in the presented population was $>15$ yrs. Recent data suggest that late introduction of inhaled steroids has little influence on lung function in patients where the airway tissue may already have been irreparably damaged [17-18]. This pathological change is attributed to a permanent ongoing airway inflammation and perhaps to the airway remodelling leading to the persistence of some airflow obstruction and bronchial hyperresponsiveness [16-21]. The potential activity of steroids on the inflammation or the remodelling of the airways could be speculated but is largely unknown.

The duration of the step-down intervals and of the whole study was based on the knowledge available on Pulmicort Turbuhaler $(\mathbb{R})$ at the time when the study was designed. According to clinical practice, $1,600 \mu \mathrm{g} \cdot \mathrm{day}^{-1}$ was assumed adequate for moderately severe asthmatic patients. In addition, $400 \mu \mathrm{g} \cdot \mathrm{day}^{-1}$ was expected to not be sufficient to bring the disease under control in these uncontrolled moderately severe patients; more patients were expected to drop-out from the study in this group. In face of the good clinical improvement achieved, longer time intervals between each titration step or prolonging the duration of the study as a whole, thus allowing for more tapering steps, would have been appropriate. The strategy employed in this study, where inhaled budesonide was reduced in the highdose treatment group only, is original in adults since only one study with a similar design has been reported in moderate-to-severe untreated young asthmatic children $[22,23]$. The current guidelines on the use of inhaled steroids in asthma advocate that the daily dose should be chosen according to the severity of the disease, mild, moderate or severe [24]. Moreover, within each severity level and appropriate dose range, the guidelines suggest a step-down approach, which is expected to allow a lower maintenance daily dose to be reached faster than if a step-up approach is used. The results of the present study, and the recent similar findings in mild asthma [25], are of importance for the routine management of asthma. The present study supports the introduction of inhaled corticosteroids at doses according to asthma severity. These results also suggest that control of symptoms may not be the most completed way to monitor the management of asthma. Reliable markers of airway inflammation or remodelling should be validated to be included in the global evaluation of the patient.

Acknowledgements. The authors thank $\mathrm{T}$. Persson, AstraZeneca R\&D, Lund for the statistical analyses, and the following investigators for their participation: P. Akoun, Hôpital Tenon, Paris; M. Aubier, Hôpital Bichat, Paris; D. Caillaud, Hôpital Sabourin, Clermont-Ferrand; Camus, Hôpital de la Trouhaude, Dijon; D. Vervloet, Hôpital Sainte Marguerite, Marseille; J.C. Pujet, C.T.A.R., Paris; M. Lavandier, Hôpital Bretonneau, Tours; J.L. Muir, Hôpital de Bois Guillaume, Rouen; D. Murciano, Hôpital Beaujon, Clichy; C. Le Merre, Chu, Nimes; Perrin-Fayolle, Ctre Hospitalier Lyon Sud,
St-Genis Laval; A. Prud'homme, Hôpital de la Gespe, Tarbes; T. Ravel, Briancon; D. Valeyre, Hôpital Avicenne, Bobigny; P. Zuck, Hôpital Notre-Dame de Bon Secours, Metz; C.H. Brambilla, Chu la Tronche, La Tronche; D. Penaud, Centre Cardiologie du Nord, St Denis.

\section{References}

1. Barnes PJ, Pedersen S, Busse WW. Efficacy and Safety of Inhaled Corticosteroids: New Developments. Am J Respir Crit Care Med 1998; 157: S1-S53.

2. Godard P, Chanez P, Redier H, Bousquet J, Michel FB. New therapeutical approaches in the treatment of asthma. Ann N Y Acad Sci 1994; 725: 367-377.

3. Guidelines for the diagnosis and management of asthma: National Heart, Lung and Blood Institute, National Asthma Education Program, Expert Panel report. J Allergy Clin Immunol 1991; 88: 425-534.

4. British Thoracic Society, British Paediatric Association, Research Unit of the Royal College of Physicians of London, King's Fund Centre, National Asthma Campaign, Royal College of General Practitioners, et al. Guidelines on the Management of Asthma. Thorax 1993; 48: S1-S24.

5. Haahtela $\mathrm{T}$, Järvinen $\mathrm{M}, \mathrm{Kava} \mathrm{T}$, et al. Comparison of a $\beta$-agonist, terbutaline, with an inhaled corticosteroid, budesonide, in newly detected asthma. $N$ Engl J Med 1991; 325: 388-392.

6. Lorentzson S, Boe J, Eriksson G, Persson P. Use of inhaled corticosteroids in patients with mild asthma. Thorax 1990; 45: 733-735.

7. Juniper EF, O'Byrne PM, Guyatt GH, Ferrie PJ, King DR. Development and validation of a questionnaire to measure asthma control. Eur Respir $J$ 1999; 14: 902-907.

8. Toogood JH, Lefcoe NM, Haines DSM, et al. A graded dose assessment of the efficacy of beclomethasone dipropionate aerosol for severe chronic asthma. J Allergy Clin Immunol 1977; 59: 298-308.

9. Laursen LC, Taudorf E, Weeke B. High-dose inhaled budesonide in treatment of severe steroid-dependent asthma. Eur J Respir Dis 1986; 68: 19-28.

10. Double-blind trial comparing two dosage schedules of beclomethasone dipropionate aerosol with a placebo in chronic bronchial asthma. Second report of the Brompton Hospital/Medical Research Council Collaborative Trial. Br J Dis Chest 1979; 73: $121-132$.

11. Busse WW, Chervinsky P, Condemi J, et al. Budesonide delivered by Turbuhaler is effective in a dosedependent fashion when used in the treatment of adult patients with chronic asthma. J Allergy Clin Immunol 1998; 101: 457-463.

12. Thorsson L, Edsbäcker S, Conradson TB. Lung deposition of budesonide from Turbuhaler $\mathbb{R}$ is twice that from a pressurized metered-dose inhaler p-MDI. Eur Respir J 1994; 7: 1839-1844.

13. Agertoft L, Pedersen S. Importance of the inhalation device on the effect of budesonide. Arch Dis Child 1993; 69: 130-133.

14. Brambilla C, Lacronique J, Wallaert B, Godard P, Duroux P. The French Budesonide Trial Group. A 3-month comparative dose-reduction study with 
inhaled beclomethasone dipropionate and budesonide in the management of moderate to severe adult asthma. Drug Invest 1994; 8: 49-56.

15. Rosi E, Ronchi MC, Grazzini M, Duranti R, Scano G. Sputum analysis, bronchial hyperresponsiveness, and airway function in asthma: Results of a factor analysis. J Allergy Clin Immunol 1999; 103: 232-237.

16. Jeffery PK, Godfrey RW, Adelroth E, Nelson F, Rogers A, Johansson SA. Effects of treatment on airway inflammation and thickening of basement membrane reticular collagen in asthma. A quantitative light and electron microscopic study. Am Rev Respir Dis 1992; 145: 890-899.

17. Selroos O, Pietinalho A, Löfroos AB, Riska H. Effect of early $v s$ late intervention with inhaled corticosteroids in asthma. Chest 1995; 108: 1228-1234.

18. Selroos O, Lofroos A, Niemisto M, Pietinalho A, Backman R, Riska H. Early introduction with inhaled steroids in asthma results in achievement of treatment goals. Am J Respir Crit Care Med 1999; 159: A627.

19. Sont JK, Willems LNA, Bel EH, van Krieken JJM, Vandenbroucke JP, Sterk PJ. Clinical control and histopathologic outcome of asthma when using airway hyperresponsiveness as an additional guide to longterm treatment. Am J Respir Crit Care Med 1999; 159: 1043-1051.
20. Haahtela T, Jarvinen M, Kava T, et al. Effects of reducing or discontinuing inhaled budesonide in patients with mild asthma. $N$ Engl J Med 1994; 331: 700-705.

21. Bai TR, Cooper J, Weir T, Wiggs B, Koelmeyer T. Airway wall thickening is greater in middle-aged compared with young adults with fatal asthma. Am J Respir Crit Care Med 1997; 155: A503.

22. Wennergren G, Nordvall SL, Hedin G, Möller C, Wille S, Åsbrink Nilsson E. Nebulized budesonide for the treatment of moderate to severe asthma in infants and toddlers. Acta Paediatr 1996; 85: 183-189.

23. Bjorkander J, Formgren H, Johansson SA, Millqvist E. Methodological aspects on clinical trials with inhaled corticosteroids: results of two comparisons between two steroid aerosols in patients with asthma. Eur J Respir Dis Suppl 1982; 122: 108-117.

24. The Global Strategy for Asthma Management and Prevention. Based on the National Institute of Health/ WHO Workshop Report. National Heart, Lung, and Blood Institute. NIH publication No 96-3659B. November 1998.

25. Van der Molen T, Meyboom-de Jong B, Mulder HH, Postma DS. Starting with a higher dose of inhaled corticosteroids in primary care asthma treatment. Am J Respir Crit Care Med 1998; 158: 121-123. 